\title{
Analysis on the pathogenic fungi in patients with superficial mycosis in the Northeastern China during 10 years
}

\author{
XIUFEN WANG, CHANGRUI DING, YULONG XU, HAOMIAO YU, SONGDI ZHANG and CUIYUN YANG \\ Department of Dermatology, The First Affiliated Hospital of Qiqihar Medical University, \\ Qiqihar, Heilongjiang 161041, P.R. China
}

Received February 24, 2020; Accepted September 25, 2020

DOI: $10.3892 /$ etm.2020.9411

\begin{abstract}
This study analyzed the infection of superficial mycosis and the relationship between the distribution characteristics of pathogenic fungi and age, time and sex in Northeast China in the past 10 years. We would like to provide a theoretical basis for the diagnosis and treatment of related diseases. From December 2008 to December 2018, 5,374 superficial mycoses from Northeast China were selected. The fungal species were identified by fungal microscopy, fungal culture, and species identification. Besides, the relationship between sex, age, time and the distribution of superficial mycosis and pathogenic fungi was analyzed. Among the 5,374 patients, the top three infections were tinea pedis $(n=1,538,28.62 \%)$, tinea cruris $(n=1,018,18.94 \%)$ and tinea corporis $(n=938$, 17.45\%). The top three pathogens were Trichophyton rubrum $(\mathrm{n}=2,849,48.65 \%)$, Trichophyton mentagrophytes $(\mathrm{n}=947$, $16.14 \%)$ and Candida spp. $(\mathrm{n}=804,13.70 \%)$. The main pathogenic fungi were dermatophytes. The age group with the highest incidence of tinea capitis was children $(n=372,6.92 \%)$. The highest incidence rate of tinea pedis was in 31-69-year adults ( $\mathrm{n}=905,16.84 \%)$; Malassezia mainly affects young people aged 15-30. Yeast and mold mostly invade the elderly patients $>60$ years old. The incidence of tinea cruris, tinea pedis and tinea corporis in male patients was higher than that in female patients. The incidence of onychomycosis in female patients was higher than that in male patients $(\mathrm{P}<0.05)$. The isolation rate of Candida, Mold, Microsporum canis, Malassezia and Sporothrix increased year by year, while that of Trichophyton rubrum, Trichophyton mentagrophyte, Trichophyton schoenleinii and Epidermophyton floccosum decreased. From December 2008 to December 2018, dermatophytes were the main pathogens of superficial mycosis in
\end{abstract}

Correspondence to: Dr Xiufen Wang, Department of Dermatology, The First Affiliated Hospital of Qiqihar Medical University, 26 Xiangyang Street, Fularji, Qiqihar, Heilongjiang 161041, P.R. China E-mail: wangxiufen1216@126.com

Key words: Northeast China, superficial mycosis, pathogenic fungi, distribution
Northeast China. The distribution of disease species and pathogenic fungi varied in different gender, age and time.

\section{Introduction}

Superficial mycosis, commonly known as ringworm, is a common infectious disease in dermatology caused by pathogenic fungi parasitic on keratin tissue $(1,2)$. Its incidence rate is increasing year by year (3). In recent years, with the wide application of broad-spectrum antibiotics, glucocorticoids, immunosuppressants and anti-tumor drugs, the possibility of secondary fungal infection in patients has increased. Therefore, fungal infection has received extensive attention (4-6). There are 1-1.5 million kinds of fungi in nature, most of which are beneficial to human beings. However, a few of them could infect human beings (or animals) and cause mycosis (7-9). According to reports, under normal circumstances, pathogenic fungi of superficial mycosis are always in a dynamic state. The pathogenic fungi could change with time and region $(10,11)$. Northeast China has high population density, a large number of ethnic groups, a large area, distinct seasons, high forest coverage, rich species, unique geographical conditions and natural and human environment. There are few studies on pathogenic fungi of superficial mycosis in this region. Therefore, this study explored the pathogenic fungi of 5,374 patients with superficial mycosis received by our hospital from December 2008 to December 2018. We analyzed the relationship between disease infection, distribution of pathogenic fungi in China and age, time, and gender, in order to provide a certain theoretical basis for the diagnosis, treatment and prevention of related diseases.

\section{Materials and methods}

Study design. From December 2008 to December 2018, 5,374 patients with superficial mycosis from northeast China were selected as research subjects. The inclusion criteria were: Patients with typical clinical symptoms; Patients diagnosed with superficial mycosis according to the medical history, physical signs and laboratory tests; The diagnosis were confirmed by more than two doctors according to the diagnostic criteria of superficial mycosis $(12,13)$. Exclusion criteria: Patients with tinea versicolor; patients took anti-fungal drugs orally within 3 months or externally within 1 month; patients with 
skin diseases with severe local suppurative infection; patients suffered from severe generalized non-infectious skin diseases; pregnant or lactating women; patients with severe systemic diseases. This study was approved by the Ethics Committee of the First Affiliated Hospital of Qiqihar Medical University. All patients signed an informed consent form.

\section{Method}

Microscopic examination of fungi. Before sampling, skin lesions were routinely disinfected with $75 \%$ alcohol. Parts that cannot be treated with alcohol could be cleaned several times with sterile physiological saline. Samples were collected from diseased nails, nail clippings, interphalangeal dandruff, hair, etc. by sterile operation. Then samples were placed on glass slides in small quantities, 2 drops of $10 \%$ potassium hydroxide solution were added on the samples. The slides were covered and placed on an alcohol lamp for 1-2 sec, and the cover glass was lightly pressed to remove bubbles. Finally, the hyphae, spores and their morphological characteristics were observed under low-power microscope (10x10) and high-power microscope (10x40) (Jiangnan BM2000). Fluorescent staining was performed if necessary.

Fungal culture and identification. Unified sabouraud medium (25 mg chloramphenicol, $15 \mathrm{~g}$ agar, $40 \mathrm{~g}$ glucose and $10 \mathrm{~g}$ peptone were thermally dissolved in $1,000 \mathrm{ml}$ distilled water at $115^{\circ} \mathrm{C}$, autoclaving for $10 \mathrm{~min}$ ) was used for basic culture. Plate multi-point culture method was used for identification. Positive microscopic examination specimens were taken, inoculated into the culture medium with an inoculation needle, 7 points at each dish. Then the specimens were placed in a $25^{\circ} \mathrm{C}$ constant temperature incubator (Shanghai Yuejin Medical Instrument Factory No. 1, China) for 2-4 weeks. Deep fungi were additionally cultured in a $37^{\circ} \mathrm{C}$ constant temperature incubator, and checked twice a week to observe the growth speed, size, morphology, color, microscopic size and conidial morphological characteristics of colonies. Suspected cases of Malassezia folliculitis were cultured on Sandcastle agar medium containing olive oil at $32^{\circ} \mathrm{C}$. If there were $\geq 3$ points of the same pathogen in 2 culture dishes, it was identified as pathogenic fungi. Sabouraud agar medium containing olive oil was used to culture Malassezia folliculitis specimens at $37^{\circ} \mathrm{C}$. Candida species were identified by the French Meria Fungus Identification Card. Dermatophyte and non-dermatophyte were mainly identified according to the characteristics of colony growth speed, morphology, size, pigment produced, colony structure, morphology of hyphae and spores under microscope.

Molecular biological identification. In order to further determine the microscopic examination and culture results, positive specimens were taken for molecular biological identification. Fungal total DNA was extracted with DNA extraction kit (Qiagen). Fungal rDNA gene conserved region (rDNA ITS) was taken as the target. Fungal universal primers ITS1 and ITS4 were used to amplify ITS region. Polymerase Chain Reaction amplification products were sequenced. Gene Bank was registered for blast comparison, and strain identification was carried out.

Statistical methods. SPSS 20.0 was used to make statistical analysis of the data. The measurement data were expressed as
Table I. Fungus and Genbank accession numbers.

Fungus

Genbank accession numbers

Trichophyton rubrum

KT155686

Trichophyton mentagrophytes

KT156074

Trichophyton schoenleinii

KT272016

Epidermophyton floccosum

KT155569

Microsporum canis

KT156124

Microsporum gypseum

KT261753

Malassezia

NR_126122

Candida

BD014669

Aspergillus fumigatus

FJ406497

Aspergillus niger

DQ374430

Sporotrichum

AF135797

mean $\pm \mathrm{SD}$, the counting data were expressed as rate, and the comparison of rates was performed by Chi-square test. The difference was statistically significant at $\mathrm{P}<0.05$.

Explanation. In the process of fungi identification, some non-superficial pathogenic fungus are often identified, such as Candida, Mold and other deep infection pathogenic fungus. However, they can also cause superficial mycosis such as tinea pedis and onychomycosis. In the clinical diagnosis and treatment process, due to the diverse morphology of skin lesions caused by fungal infections, multi-species co-infection often occurs during the infection process. Damage to the surface of the skin also increases the infection rate of non-superficial fungal pathogens and may aggravate the progression of the disease (such as sporotrichosis). Therefore, considering the clinical significance of these fungus, they were not deleted in the result analysis. Although they are not superficial mycosis, they are still included in the result data.

\section{Results}

Study population characteristics. There were 2,863 males and 2,511 females. The patients were aged 6-70 years, and the average age was $36.39 \pm 17.38$ years. The duration of the disease ranged from $(0.25-50)$ years, with an average course of $8.81 \pm 10.56$ years. Among them, 3,875 patients had a history of mycosis in their families or relatives, and 1,891 patients had the experience of feeding pet cats and dogs in their families.

Fungus and Genbank accession numbers. The obtained DNA was compared with blast sequence, and the relative Genbank accession numbers are shown in Table I.

Clinical types of superficial mycosis and distribution of pathogenic fungi. A total of 5,374 patients suspected of superficial mycosis were included in this study. Among them, there were 1,538 cases of tinea pedis $(28.62 \%), 1,018$ cases of tinea cruris (18.94\%), 938 cases of tinea corporis (17.45\%), 773 cases of onychomycosis (14.38\%), 496 cases of tinea capitis $(9.23 \%)$, 394 cases of tinea manuum (7.33\%), 164 cases of Malassezia 
Table II. Clinical types of superficial dermatomycosis and distribution of pathogenic bacteria.

\begin{tabular}{|c|c|c|c|c|c|c|c|c|c|}
\hline Type of bacteria & $\begin{array}{l}\text { Tinea } \\
\text { pedis }\end{array}$ & $\begin{array}{l}\text { Tinea } \\
\text { cruris }\end{array}$ & $\begin{array}{l}\text { Tinea } \\
\text { corporis }\end{array}$ & $\begin{array}{l}\text { Onycho- } \\
\text { mycosis }\end{array}$ & $\begin{array}{l}\text { Tinea } \\
\text { capitis }\end{array}$ & $\begin{array}{c}\text { Tinea } \\
\text { manuum }\end{array}$ & $\begin{array}{l}\text { Malassezia } \\
\text { folliculitis }\end{array}$ & $\begin{array}{l}\text { Sporotri- } \\
\text { chosis }\end{array}$ & $\begin{array}{c}\text { Total } \\
\text { [strains }(\%)]\end{array}$ \\
\hline Dermatophyte & 1,502 & 895 & 824 & 472 & 570 & 423 & 0 & 0 & $4,686(79.87)$ \\
\hline Trichophyton rubrum & 1,012 & 523 & 605 & 377 & 47 & 285 & 0 & 0 & $2,849(48.56)$ \\
\hline $\begin{array}{l}\text { Trichophyton } \\
\text { mentagrophytes }\end{array}$ & 309 & 212 & 83 & 51 & 205 & 87 & 0 & 0 & $947(16.14)$ \\
\hline $\begin{array}{l}\text { Trichophyton } \\
\text { schoenleinii }\end{array}$ & 17 & 0 & 0 & 12 & 73 & 5 & 0 & 0 & $107 \quad(1.82)$ \\
\hline $\begin{array}{l}\text { Epidermophyton } \\
\text { floccosum }\end{array}$ & 58 & 21 & 2 & 4 & 0 & 16 & 0 & 0 & 101 (1.72) \\
\hline Microsporum canis & 67 & 98 & 121 & 8 & 184 & 19 & 0 & 0 & 497 (8.47) \\
\hline $\begin{array}{l}\text { Microsporum } \\
\text { gypseum }\end{array}$ & 39 & 41 & 13 & 20 & 61 & 11 & 0 & 0 & $185(3.15)$ \\
\hline Saccharomyces & 178 & 93 & 87 & 383 & 13 & 50 & 0 & 0 & $804(13.70)$ \\
\hline Candida & 178 & 93 & 87 & 383 & 13 & 50 & 0 & 0 & 804 (13.70) \\
\hline Aspergillus & 19 & 30 & 27 & 77 & 0 & 7 & 0 & 0 & $160 \quad(2.73)$ \\
\hline Aspergillus fumigatus & 11 & 23 & 22 & 53 & 0 & 5 & 0 & 0 & 114 (1.94) \\
\hline Aspergillus niger & 8 & 7 & 5 & 24 & 0 & 2 & 0 & 0 & $46(0.78)$ \\
\hline Malassezia & 0 & 0 & 0 & 0 & 0 & 0 & 164 & 0 & $164(2.80)$ \\
\hline Dimorphic fungi & 0 & 0 & 0 & 0 & 0 & 0 & 0 & 53 & $53(0.90)$ \\
\hline Sporotrichum & 0 & 0 & 0 & 0 & 0 & 0 & 0 & 53 & $53 \quad(0.90)$ \\
\hline
\end{tabular}

Table III. Comparison of main clinical types of superficial dermatomycosis in patients of different sex [cases $(\%)]$.

\begin{tabular}{lccccccccc}
\hline Gender & $\begin{array}{c}\text { Number } \\
\text { of cases }\end{array}$ & $\begin{array}{c}\text { Tinea } \\
\text { pedis }\end{array}$ & $\begin{array}{c}\text { Tinea } \\
\text { cruris }\end{array}$ & $\begin{array}{c}\text { Tinea } \\
\text { corporis }\end{array}$ & $\begin{array}{c}\text { Onycho- } \\
\text { mycosis }\end{array}$ & $\begin{array}{c}\text { Tinea } \\
\text { capitis }\end{array}$ & $\begin{array}{c}\text { Tinea } \\
\text { manuum }\end{array}$ & $\begin{array}{c}\text { Malassezia } \\
\text { folliculitis }\end{array}$ & $\begin{array}{c}\text { Sporotri- } \\
\text { chosis }\end{array}$ \\
\hline Male & 2,863 & $1,059(36.99)$ & $683(23.86)$ & $659(23.02)$ & $237(8.28)$ & $308(10.76)$ & $269(9.40)$ & $125(4.37)$ & $30(1.05)$ \\
Female & 2,511 & $479(19.08)$ & $335(13.34)$ & $279(11.11)$ & $695(27.68)$ & $275(10.95)$ & $211(8.40)$ & $39(1.55)$ & $23(0.92)$ \\
$\chi^{2}$ & & 210.123 & 96.323 & 131.630 & 351.223 & 0.052 & 1.621 & 35.776 & 0.238 \\
$P_{\text {value }}$ & & $<0.05$ & $<0.05$ & $<0.05$ & $<0.05$ & 0.820 & 0.203 & $<0.05$ & 0.625 \\
\hline
\end{tabular}

${ }^{\mathrm{a} C h i}$-square $\left(\chi^{2}\right)$ test was used.

folliculitis $(3.05 \%)$, and 53 cases of sporotrichosis $(0.99 \%)$. Fungal culture was carried out on the specimen, and a total of 5,867 strains of 11 species were isolated. The distribution of pathogenic fungi is shown in Table II.

Distribution of superficial mycosis, pathogenic fungi and age. In this study, the patients with superficial mycosis aged 6-70 years, with an average age of $36.39 \pm 17.38$. Patients were grouped according to the age: Child group, $0-15$ years old (516 cases, $9.60 \%$ ); young people group, $15-30$ years old (1,229 cases, 22.87\%); adults group, 31-60 years old $(2,656$ cases, $49.42 \%)$; the elderly group, over 60 years old (973 cases, $18.11 \%$ ).

The number of patients of all ages and diseases is shown in Fig. 1. The group with the highest incidence of tinea capitis was the children $(n=372,6.92 \%)$. The group with the highest incidence of tinea pedis was the adults $(n=905,16.84 \%)$, and the incidence of tinea pedis was higher than any other mycoses in all age groups. Onychomycosis was concentrated in the young people group and the adults group.

The age of the patients and the distribution of pathogenic fungi are shown in Fig. 2, in which Malassezia mainly invades young people, yeast and mold mainly invades elderly patients aged over 60 years.

Distribution of superficial mycosis and sex. The prevalence rate of tinea pedis, tinea cruris, tinea corporis and Malassezia folliculitis in men was higher than that in women, and the prevalence rate of onychomycosis in women was higher than that in men $(\mathrm{P}<0.05)$. The specific data are shown in Table III.

Distribution of superficial mycosis, pathogenic fungi and time. As shown in Fig. 3, from 2008 to 2018, the incidence of tinea pedis, tinea corporis, tinea manuum, and tinea cruris showed a downward trend among 5,374 patients with superficial mycosis admitted to the dermatological department 


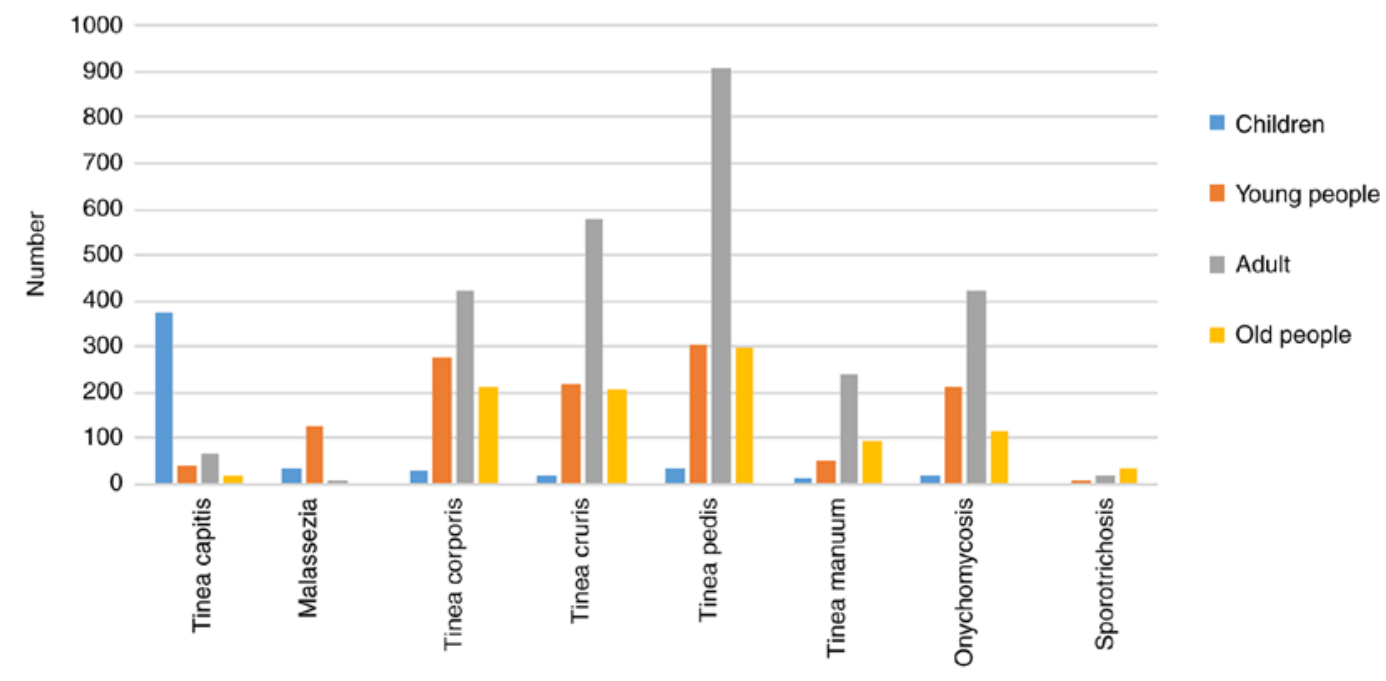

Figure 1. Distribution of superficial mycosis in different ages.

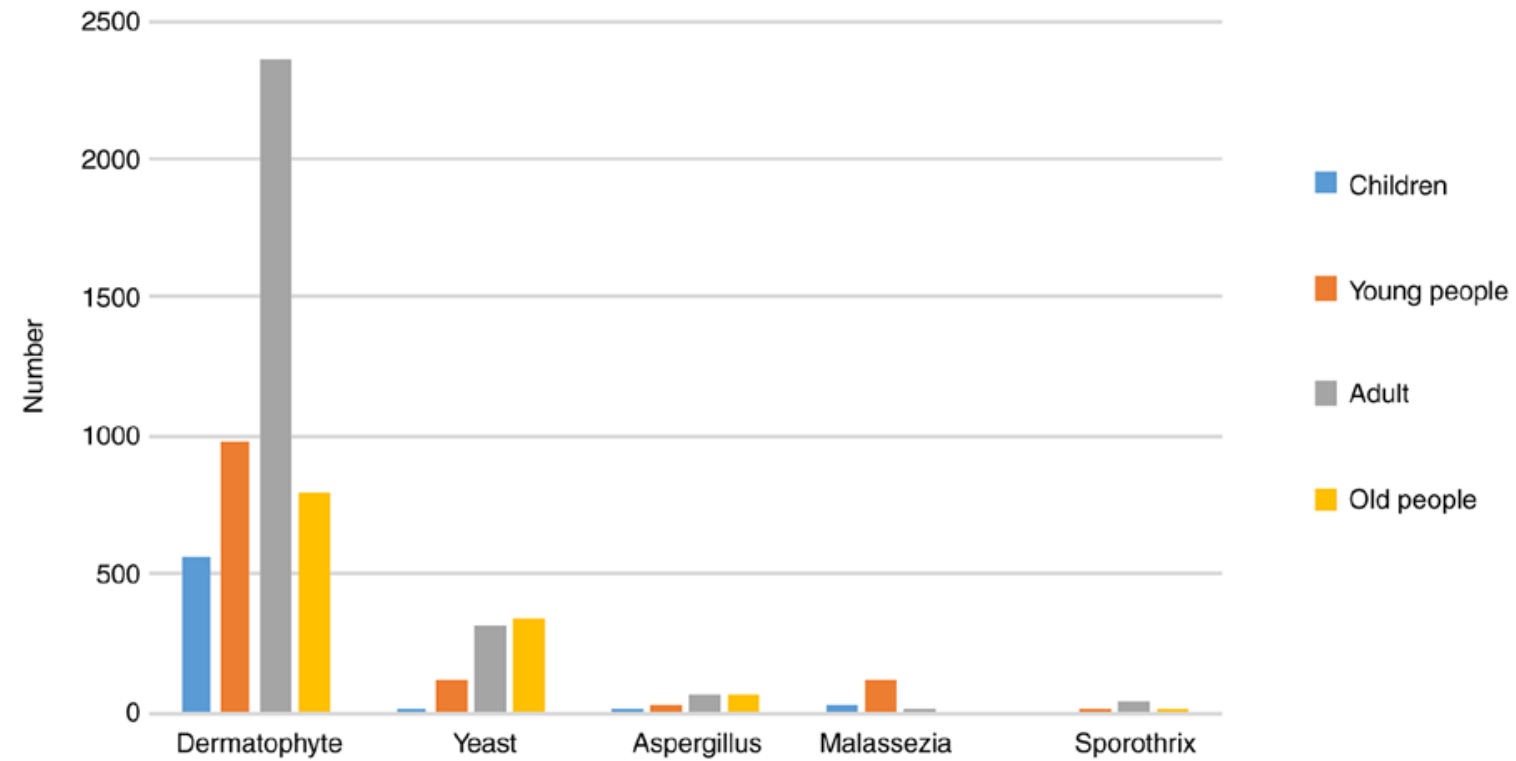

of our hospital from the northeast region. The incidence of Malassezia folliculitis, onychomycosis, and sporotrichosis showed an upward trend. The incidence of tinea capitis first decreased and then increased.

As shown in Fig. 4, in terms of the isolation rate of pathogenic fungi, Candida, Mold, Microsporum canis, Malassezia and sporothrix significantly increased, while Trichophyton rubrum, Trichophyton mentagrophytes, Trichophyton schoenleinii and Epidermophyton floccosum showed a downward trend.

\section{Discussion}

Superficial mycosis is a common disease in dermatology, which is characterized by common occurrence, multiple occurrence and recurrence, with a prevalence rate of about $20 \%$ worldwide $(14,15)$. In recent years, the incidence rate of individual superficial mycosis has increased year by year, and the types of pathogenic fungi are also diversified (16). In 5,743 cases of superficial mycosis collected in this subject, tinea pedis was the most common disease, followed by tinea cruris and onychomycosis. The top three pathogenic fungi of superficial mycosis isolated in the 10 years from 2008 to 2018 were Trichophyton rubrum, Trichophyton mentagrophytes and Candida. The results were different from the previous research results in Jilin (17). However, Trichophyton rubrum is still the first pathogen species, and most studies in China and worldwide also show that Trichophyton rubrum is the primary pathogen of superficial mycosis (18-21). The difference is that in northern China, Trichophyton mentagrophytes and Microsporum canis are often the second and third pathogenic fungi, while in southern China, Candida is often the second pathogenic fungi (22). The distribution difference of strains is affected by climate, population composition, lifestyle and socio-economic conditions, resulting in different epidemiological profiles of dermatophytes in different geographical 
0.3500

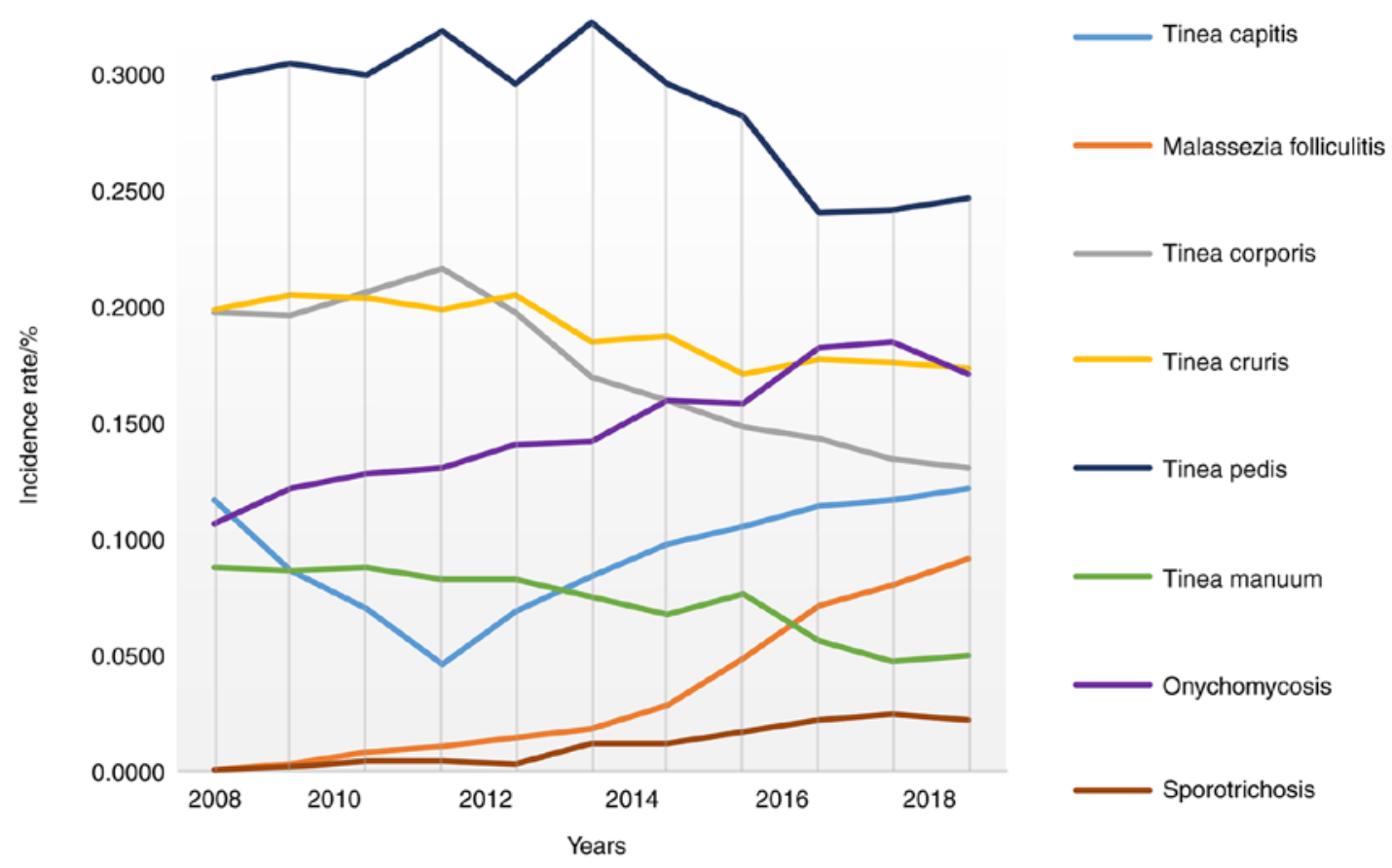

Figure 3. Distribution of incidence rate of superficial mycosis in different years.

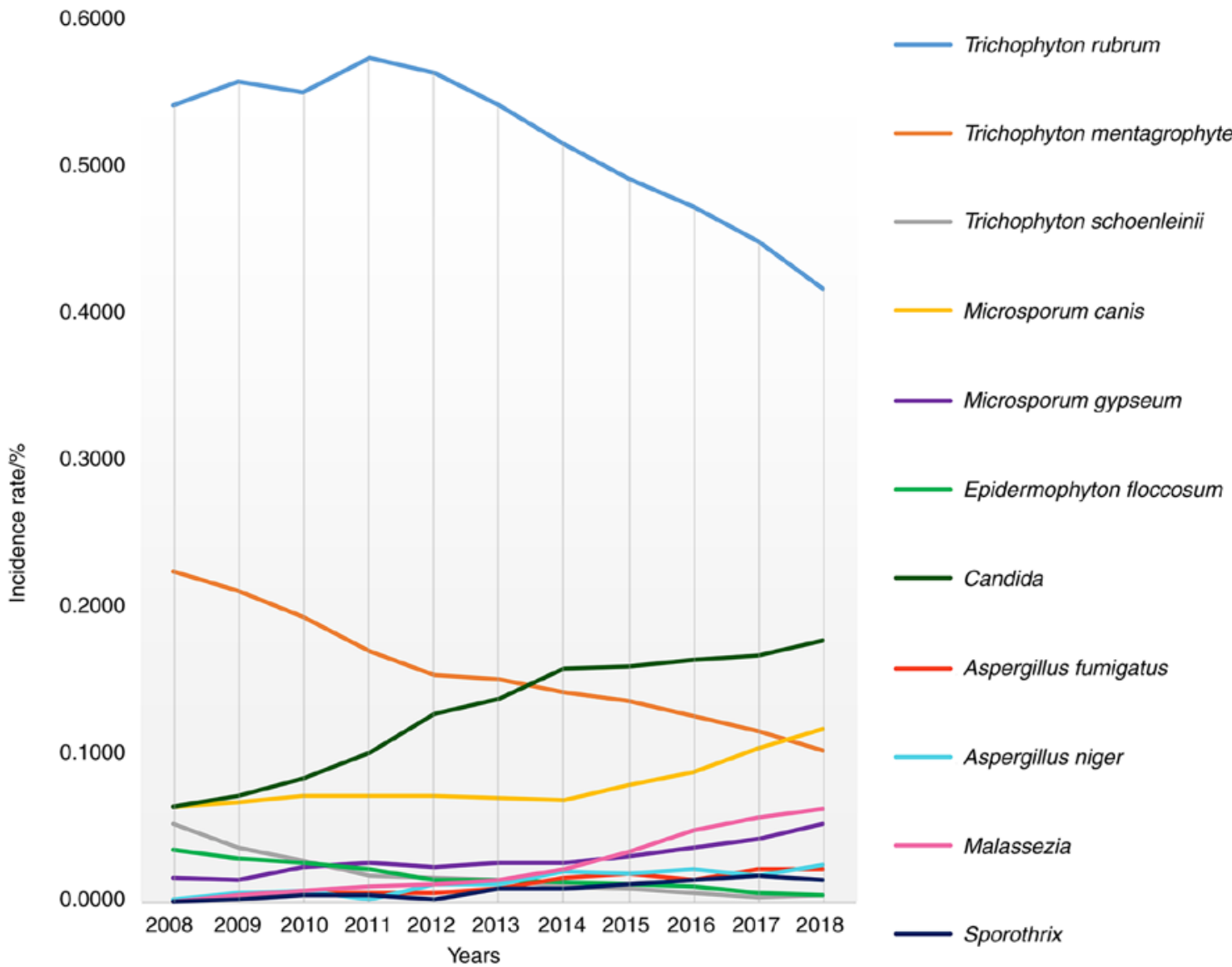

Figure 4. Distribution of pathogenic fungi separation rate in different years.

regions $(23,24)$. According to the existing diagnostic criteria, tinea versicolor is a superficial fungal disease. However, when the study was designed, the diagnosis of tinea versicolor was controversial. Some scholars believed that tinea versicolor 
was not a fungal infection. Therefore, to avoid controversial conclusions, tinea versicolor was included in this study.

In this study, tinea pedis infection was mainly in adults. Patients of this age were the main labor force. They have more opportunities to contact pathogenic fungi due to work or housework, which may lead to an increase in the incidence rate. Tinea manuum is similar to tinea pedis, and the composition of pathogenic fungi is basically the same. The reason may be that tinea manuum can be secondary to tinea pedis and is often manifested as the two feet-one hand syndrome. Superficial fungal infection can also spread among different parts of patients. For example, tinea pedis can cause tinea manuum, tinea corporis, tinea cruris and onychomycosis. Approximately $1 / 3$ of tinea pedis patients are accompanied by onychomycosis (25). There are more male patients with tinea pedis than female patients; tinea cruris and tinea corporis also have similar rules. After analyzing the causes, we found that it may be related to male physiological structure, more active habits, and exuberant secretion of sweat glands and sebaceous glands, which is more conducive to the growth of dermatophytes. Female patients with onychomycosis are more than male patients, which may be due to the subjective consciousness, occupation and living habits of females. This is basically consistent with the research results in other regions (26-28). Therefore, in daily life, we should strengthen the related propaganda of mycosis and improve the awareness of visiting a doctor.

Tinea capitis is mainly concentrated in children, and its pathogenic fungi are Trichophyton mentagrophytes and Microsporum canis. Microsporum canis is a kind of animal-friendly fungus. According to the results of this survey, the isolation rate in Microsporum canis has gradually increased in recent years, which may be caused by the increasing popularity of pet raising. However, the incidence of tinea capitis in children is the highest, which may be related to children's poor resistance and close contact with pets such as cats and dogs. Before 1985, the main pathogen of tinea capitis in northeast China was Trichophyton schoenleinii, which is a kind of family fungus. However, in this study, the isolation rate of Trichophyton schoenleinii decreased year by year, which may be related to the economic development in northeast China. Relevant studies also showed that with the development of China's economy in the past 60 years, pets have become the most likely source of tinea capitis in modern society instead of the early human-to-human transmission model (29). The difference with this result is that the isolation rate of Microsporum canis in Jiangxi, Anhui and Xinjiang is relatively low. Trichophyton violaceum is the dominant species in these regions, accounting for $53.38,46.17$ and $48.55 \%$ respectively (30), which may be related to the differences in lifestyle in different regions. Therefore, in northeast China, pet health publicity and education should be strengthened. If skin fungal infection from pets is found, we should treated both humans and animals.

Among the changes of pathogenic fungi, the changes of Candida and Mold should be observed by doctors. This study showed that the isolation rate of Candida and Mold is increasing year by year. Candida and Mold were common conditioned pathogen, which could cause severe invasive fungal infection, such as invasive candidiasis, invasive aspergillosis. It mainly affected patients with low immune function, and the mortality rate was extremely high (31). Fungal infection is not uncommon in systemic diseases with hypoimmunity. Over $90 \%$ of AIDS patients have at least one skin disease, especially infectious diseases involving skin and mucosa, with a prevalence rate of $60 \%$ (32). In recent years, the decrease of immunity and dysbacteriosis of organisms have increased the possibility of infection caused by these fungi due to the increase of various chronic consumptive diseases, the extensive application of corticosteroids and immunosuppressants, and the long-term application of broad-spectrum antibiotics. In clinical work, medical workers should pay more attention to fungal infection, apply antibiotics, corticosteroids and anti-tumor drugs more reasonably, and improve the diagnosis rate and treatment effect of superficial mycosis of skin $(33,34)$. In superficial mycosis, Candida and Mold mainly cause onychomycosis, and the increasing isolation rate year by year also suggests that doctors should consider broad-spectrum antifungal drugs with consideration of dermatophyte, yeast and mould.

In addition, the changes of Malassezia deserve attention. Malassezia caused by this strain is often clinically misdiagnosed, and the misdiagnosis rate is relatively high. Malassezia folliculitis has similar clinical symptoms to acne vulgaris and seborrheic dermatitis. It is often misdiagnosed with antibiotics and corticosteroid preparations during treatment, resulting in lingering and even aggravating diseases. This study and many other domestic studies show that the incidence rate of Malassezia folliculitis has increased each year recently (35-37). It mostly invades young people, who are at an immature stage of psychology and physiology, and pay more attention to their appearance and image. Repeated occurrence of the disease is easy to burden young people's psychology and has a great impact on their growth.

Strictly speaking, sporotrichosis does not belong to superficial mycosis, but its incidence rate is gradually increasing and it also has the manifestation of invading superficial skin. So it is also included in the discussion here. Sporothrix is prevalent in northeast China and its incidence rate is on the rise. During 1991-2007, Jilin, China reported >2,000 confirmed cases of sporotrichosis, making northeast China one of the most serious epidemic areas of sporotrichosis in China and even in the world (38). Jiangsu and Guangdong are the main areas in southern China, but the incidence rate is far lower than that in northeast China. Due to its various skin lesions, it is often misdiagnosed as inflammatory granuloma and skin tuberculosis. Although most sporotrichosis can be cured, it takes a long time, and if proper drugs are not selected, it is easy to aggravate infection. Therefore, in clinical work, we should strengthen the understanding of related diseases and rationally choose drugs. With the increase in the number of immunocompromised patients, the epidemiological monitoring of sporotrichosis is increasingly needed, and additional protective measures should be taken to avoid infection during agricultural activities.

This study showed that the distribution of superficial mycosis and its pathogenic fungi in northeast China has certain regularity and is affected by age, sex and time. With the passage of time, the distribution of various pathogenic fungi has changed correspondingly, and targeted treatment programs should be implemented according to its trend. In our daily life, 
we should also strengthen the general public's awareness of fungal infection and persist in carrying out epidemiological monitoring of superficial mycosis. It is of great significance to the prevention and treatment of superficial mycosis. This study also has limitations. The inclusion of tinea versicolor was not included (the diagnosis of tinea versicolor was controversial at the beginning of the study, but it is now clear that it is a superficial fungal disease caused by pityrosporum infection). The negative samples were abandoned, which makes the results biased. In the future, more rigorous research design should be carried out to better serve clinical diagnosis and treatment.

\section{Acknowledgements}

Not applicable.

\section{Funding}

Project of Qiqihar Science and Technology Plan (SFZD-2013118).

\section{Availability of data and materials}

The datasets used and/or analyzed during the current study are available from the corresponding author on reasonable request.

\section{Authors' contributions}

XW, CD, YX and HY conceived and designed the study, and drafted the manuscript. XW, CD, SZ and CY collected, analyzed and interpreted the experimental data. XW revised the manuscript for important intellectual content. All authors read and approved the final manuscript.

\section{Ethics approval and consent to participate}

The study was approved by the Ethics Committee of The First Affiliated Hospital of Qiqihar Medical University. Signed informed consents were obtained from the patients and/or guardians.

\section{Patient consent for publication}

Not applicable.

\section{Competing interests}

The authors declare that they have no competing interests.

\section{References}

1. Feng W, Chen C, Mo S, Qi C, Gong J,Li XN, Zhou Q,Zhou Y,Li D, Lai Y, et al: Highly oxygenated meroterpenoids from the Antarctic fungus Aspergillus terreus. Phytochemistry 164: 184-191, 2019.

2. Bezshapochny SB, Zachepilo SV, Polyanskaya VP, Bobrova NA and Fedorchenko VI: Opportunistic mycoses of ENT organs. Part 1. Vestn Otorinolaringol 83: 67-71, 2018 (In Russian).

3. Lao M, Wang X, Ding M, Yang Z, Chen H, Liang L, Zhan Z and Chen D: Invasive fungal disease in patients with systemic lupus erythematosus from Southern China: A retrospective study. Lupus 28: 77-85, 2019.
4. Upadhyay V, Kumar A, Singh AK and Pandey J: Epidemiological characterization of dermatophytes at a tertiary care hospital in Eastern Uttar Pradesh, India. Curr Med Mycol 5: 1-6, 2019.

5. Moriello KA: Decontamination of 70 foster family homes exposed to Microsporum canis infected cats: A retrospective study. Vet Dermatol 30: 178-e55, 2019.

6. Hilmioğlu-Polat S, Seyedmousavi S, Ilkit M, Hedayati MT, Inci R, Tumbay E and Denning DW: Estimated burden of serious human fungal diseases in Turkey. Mycoses 62: 22-31, 2019.

7. Alvarez-Moreno CA and Combariza JF: Risk of invasive fungal infections during hospital construction: How to minimize its impact in immunocompromised patients. Curr Opin Infect Dis 32: 322-329, 2019.

8. Rouzaud C, Chosidow O, Brocard A, Fraitag S, Scemla A Anglicheau D, Bouaziz JD, Dupin N, Bougnoux ME, Hay R, et al: Severe dermatophytosis in solid organ transplant recipients: A French retrospective series and literature review. Transpl Infect Dis: Feb 20, 2018 (Epub ahead of print). doi: 10.1111/tid.12799.

9. Deptuła A, Trejnowska E, Dubiel G, Żukowski M, Misiewska-Kaczur A, Ozorowski T and Hryniewicz W: Prevalence of healthcare-associated infections in Polish adult intensive care units: Summary data from the ECDC European Point Prevalence Survey of hospital-associated infections and antimicrobial use in Poland 2012-2014. J Hosp Infect 96: 145-150, 2017.

10. Nenoff P, Verma SB, Vasani R, Burmester A, Hipler UC, Wittig F, Krüger C, Nenoff K, Wiegand C, Saraswat A, et al: The current Indian epidemic of superficial dermatophytosis due to Trichophyton mentagrophytes - A molecular study. Mycoses 62: 336-356, 2019.

11. Otašević S, Momčilović S, Golubović M, Ignjatović A, Rančić N, Đorđević M, Ranđelović M, Hay R and Arsić-Arsenijević V: Species distribution and epidemiological characteristics of superficial fungal infections in Southeastern Serbia. Mycoses 62: 458-465, 2019.

12. Dainton $\mathrm{C}$ and $\mathrm{Chu} \mathrm{CH}$ : A narrative review of dermatologic protocols for primary care medical service trips in Latin America and the Caribbean. Int J Dermatol 56: 1425-143, 2017.

13. Singh S, Ehsani-Chimeh N, Kornmehl $\mathrm{H}$ and Armstrong AW: Quality of life among dermatology patients: A systematic review of investigations using qualitative methods. G Ital Dermatol Venereol 154: 72-78, 2019.

14. Nilsson K, Friberg M, Rollman O and Tano E: Impact of prolonged storage of clinical samples at $4^{\circ} \mathrm{C}$ on the recovery of dermatophytes by culture or PCR analysis. J Mycol Med 29: 1-6, 2019.

15. Leung AKC, Leong KF and Lam JM: Tinea imbricata: An overview. Curr Pediatr Rev 15: 170-174, 2019.

16. Farag AGA, Hammam MA, Ibrahem RA, Mahfouz RZ, Elnaidany NF, Qutubuddin M and Tolba RRE: Epidemiology of dermatophyte infections among school children in Menoufia Governorate, Egypt. Mycoses 61: 321-325, 2018.

17. Gawdzik A, Nowogrodzka K, Hryncewicz-Gwóźdź A, Maj J, Szepietowski J and Jankowska-Konsur A: Epidemiology of dermatomycoses in southwest Poland. Postepy Dermatol Alergol 36: 604-608, 2019.

18. de Albuquerque Maranhão FC, Oliveira-Júnior JB, Dos Santos Araújo MA and Silva DMW: Mycoses in northeastern Brazil: Epidemiology and prevalence of fungal species in 8 years of retrospective analysis in Alagoas. Braz J Microbiol 50: 969-978, 2019.

19. Antuori A, Fernández G, Fernández A, Alcaide M, Boada A, Bielsa MI, Romaní N and Matas L: Epidemiology of dermatophytic infections between 2008 and 2017 in Barcelona, Spain. Enferm Infecc Microbiol Clin 37: 642-647, 2019.

20. Sen S, Borah SN, Kandimalla R, Bora A and Deka S: Efficacy of a rhamnolipid biosurfactant to inhibit Trichophyton rubrum in vitro and in a mice model of dermatophytosis. Exp Dermatol 28: 601-608, 2019.

21. Bitencourt TA, Oliveira FB, Sanches PR, Rossi A and Martinez-Rossi NM: The prp4 kinase gene and related spliceosome factor genes in Trichophyton rubrum respond to nutrients and antifungals. J Med Microbiol 68: 591-599, 2019.

22. Cai W, Lu C, Li X, Zhang J, Zhan P, Xi L, Sun J and Yu X: Epidemiology of superficial fungal infections in Guangdong, Southern China: A retrospective study from 2004 to 2014. Mycopathologia 181: 387-395, 2018.

23. Havlickova B,Czaika VA and Friedrich M: Epidemiological trends in skin mycoses worldwide. Mycoses 51 (Suppl 4): S2-S15, 2008.

24. Ginter-Hanselmayer G, Weger W, Ilkit $M$ and Smolle J: Epidemiology of tinea capitis in Europe: Current state and changing patterns. Mycoses 50 (Suppl 2): S6-S13, 2007. 
25. Nasr A, Vyzantiadis TA, Patsatsi A, Louka A, Ioakimidou A Zachrou E, Chavale A, Kalabalikis D, Malissiovas N and Sotiriadis D: Epidemiology of superficial mycoses in Northern Greece: A 4-year study. J Eur Acad Dermatol Venereol 30: 837-839, 2016.

26. Gawaz A and Weisel G: Mixed infections are a critical factor in the treatment of superficial mycoses. Mycoses 61: 731-735, 2018.

27. de Hoog S, Monod M, Dawson T, Boekhout T, Mayser P and Gräser Y: Skin fungi from colonization to infection. Microbiol Spectr Jul 5, 2017 (Epub ahead of print). doi: 0.1128/microbiolspec.FUNK-0049-2016.

28. Bond R: Superficial veterinary mycoses. Clin Dermatol 28: 226-236, 2010

29. Zhan P, Geng C, Li Z, Jin Y, Jiang Q, Tao L, Luo Y, Xiong Z, $\mathrm{Wu} \mathrm{S}, \mathrm{Li} \mathrm{D}$, et al: Evolution of tinea capitis in the Nanchang area, Southern China: A 50-year survey (1965-2014). Mycoses 58: 261-266, 2015.

30. Zhan P, Li D, Wang C, Sun J, Geng C, Xiong Z, Seyedmousavi S, Liu W and de Hoog GS: Epidemiological changes in tinea capitis over the sixty years of economic growth in China. Med Mycol 53: 691-698, 2015.

31. Chen M, Xu Y, Hong N, Yang Y, Lei W, Du L, Zhao J, Lei X, Xiong L, Cai L, et al: Epidemiology of fungal infections in China. Front Med 12: 58-75, 2018.

32. Tschachler E: The dermatologist and the HIV/AIDS pandemic. Clin Dermatol 32: 286-289, 2014.
33. Fay VDS, Rodrigues DMG, Goncalves SMB, Gregianini TS and Bonamigo RR: Drug susceptibility in emerging fungal infections: Tests with fluconazole, itraconazole, and amphotericin B. An Bras Dermatol 93: 462-464, 2018.

34. Wypij M, Czarnecka J, Dahm H, Rai M and Golinska P: Silver nanoparticles from Pilimelia columellifera subsp. pallida SL19 strain demonstrated antifungal activity against fungi causing superficial mycoses. J Basic Microbiol 57: 793-800, 2017.

35. Durdu M, Güran M and Ilkit M: Epidemiological characteristics of Malassezia folliculitis and use of the May-Grünwald-Giemsa stain to diagnose the infection. Diagn Microbiol Infect Dis 76: 450-457, 2013.

36. Tsai YC, Wang JY, Wu YH and Wang YJ: Clinical differences in pediatric and adult Malassezia folliculitis: Retrospective analysis of 321 cases over 9 years. J Am Acad Dermatol 81: 278-280, 2019.

37. Harada K, Saito M, Sugita T and Tsuboi R: Malassezia species and their associated skin diseases. J Dermatol 42: 250-257, 2015.

38. Chakrabarti A, Bonifaz A, Gutierrez-Galhardo MC, Mochizuki T and Li S: Global epidemiology of sporotrichosis. Med Mycol 53: 3-14, 2015.

This work is licensed under a Creative Commons Attribution-NonCommercial-NoDerivatives 4.0 International (CC BY-NC-ND 4.0) License. 